\title{
Comparison of Colony Morphology, Sporophore Characters and Yield Performance of Wild and Cultivated Milky Mushroom Isolates
}

\author{
Priyadharshini Bhupathi* (D) and Krishnamoorthy Akkana Subbaiah \\ Mushroom Research Laboratory, Department of Plant Pathology, Tamil Nadu Agricultural University, \\ Coimbatore - 641 003, Tamil Nadu, India.
}

\begin{abstract}
The present investigation was carried out to identify morphology and yield performance of milky mushroom isolates for both the wild and cultivars. In this study, 17 wild isolates (CBE-TNAU-1513 to 1526, CBE- TNAU-1603, 1604 and CBE-TNAU-1701), seven cultivated strains (Cl-13-02, 04, 06 and Cl-14-02, 03, 04 and $\mathrm{Cl}-14-06)$ and Tamil Nadu Agricultural University APK2 (C. indica) variety were compared. Colony characters of all the 25 isolates of milky mushroom grown on PDA medium were recorded. Among the isolates, CBE- TNAU-1523, CBE-TNAU-1603 and APK2 were found to be fast growing covering the maximum radial growth of $90 \mathrm{~mm}$ in Petri dish within 7 days. In order to find out the best performing wild isolate, the observations have been recorded with morphometric characters viz., days for spawn run (DFSR), days for pin head formation (DFPF), pileus and stipe measurements including the pileus: stipe ratio for all the strains were recorded. The complete spawn run was faster in APK2 (10.3 d). However, the mycelial impregnation in the casing soil was comparatively quick with the isolate CBE-TNAU-1515, which also reflected in early pinning with this isolate (8.4d). The strains viz., CBE-TNAU-1517, 1521, 1522, 1523 and APK2 possessed milky white, robust and companulate sporodomes having thick cylindrical stipe, which was found to be moderately bulged at the base. When selected based on yield attributes, significantly increased yield was obtained with the strain CBE-TNAU-1523 (972 g per bed with 194.5 per cent bio-efficiency).
\end{abstract}

Keywords: Colony morphology; wild isolate; milky mushroom; yield attributes; pileus: stipe ratio.

*Correspondence: priya2bhupathy@gmail.com

(Received: 29 June 2019; accepted: 18 November 2019)

Citation: Priyadharshini Bhupathi, Krishnamoorthy Akkana Subbaiah, Comparison of Colony Morphology, Sporophore Characters and Yield Performance of Wild and Cultivated Milky Mushroom Isolates, J Pure Appl Microbiol., 2019; 13(4):2405-2419. https:// doi.org/10.22207/JPAM.13.4.57

(C) The Author(s) 2019. Open Access. This article is distributed under the terms of the Creative Commons Attribution 4.0 International License which permits unrestricted use, sharing, distribution, and reproduction in any medium, provided you give appropriate credit to the original author(s) and the source, provide a link to the Creative Commons license, and indicate if changes were made. 


\section{INTRODUCTION}

Edible mushroom species have been found in association with 13,000-year-old archaeological sites in Chile. The magnitude of fungal diversity was estimated to be at least 1.5 million species of which, 140,000 species produce fruiting bodies of sufficient size and suitable structure to be considered as macro fungi (Chang and Miles 1992). The man who lived between 3400 and 3100 BC in Europe was found with two types of wild edible mushrooms viz., Boletus edulis and Tricholoma sp. The first reliable evidence of mushroom consumption dates to several hundred years BC in China (Boa, 2004), they have found not only for nutrition and taste but also for their healing properties

Calocybe indica (P\&C), commonly known as milky mushroom, introduced from India is highly suitable for cultivation in the warm humid tropical regions (Purkayastha and Chandra, 1976; Thakur and Singh, 2014). Sustainable yield, robust nature, alluring white colour, long shelf-life and potential market expansion of milky mushroom have attracted considerable attention by growers and consumers in India (Krishnamoorthy et al., 1998; Chakraborty and Sikdar, 2010, Krishnamoorthy and Balan, 2015). The mushroom is exceedingly rich in protein, lipids, fibre, minerals, carbohydrates and contains essential amino acids (Mallavadhani et al., 2006 and Alam et al., 2008). Milky mushroom is also an admirable source of thiamine, riboflavin, nicotinic acid, pyridoxine and ascorbic acid. It grows well at a temperature range of $25-35^{\circ} \mathrm{C}$ with relative humidity more than 85 per cent (Krishnamoorthy, 1995; Pani, 2012). Therefore, it can be cultivated throughout the year in the tropical plains of India. Total commercial production techniques and the first milky mushroom variety Calocybe indica var. APK2 was introduced for the first time in the world by Krishnamoorthy et al. (1998).

Some of the tropical mushroom species belonging to the proposed new genus, have had a complex and confusing identification between the species, owing to the presence of same morphological characters (Pegler et al., 1998). Calocybe indica has been placed under Calocybe - Sect. I. Calocybe (Guttatae) (Fr.) Sing. and belongs to the family Tricholomataceae of the order Agaricales (Singer, 1961). The hymenophoral trama, which is regular, but for the slight divergence below the hymenia. The pileopellis is filamentous and the basidia are carminophillic. Spores are thin walled, hyaline, which lack highly differentiated cystidia, although several cylindrical units with granular contents and clamp connections are present. This species is very close to $C$. gambosa (Fr.) Sing. differing in the slightly larger and broadly ellipsoid basidiophore. C. eborina reported by Pegler (1983) is also a pure white species whereas, C. cyanocephala (Pat.) Pegler and C. cyanea Singer ex Redhead \& Singer contain violet or yellow pigments in the pileus, stipe and lamellae. Using DNA sequences, C. cyanea has been closely allied to C. carnea. $C$. cyanea appears to be more closely related to the temperate species, C. onychina (Fr.) Donk, typically found in coniferons forests in Europe and North America. Even though they are clearly different species, these two taxa share several similarities of macroscopic and microscopic features.

Calocybe bipigmentata (Singer) has dark reddish brown pileus; $C$. alneti (Singer) has convex-depressed pileus with a pale greyish brown disc and the stipe appears fuscous yellow; $\quad C$. coniceps (Singer) has pale cream pileus with a greyish brown disc; C. atropapillata (Singer) has bluish grey pileus; $C$. cyanocephala (Pat.) Pegler has lamellae with violaceous or lilac hues (Singer, 1948). Appearance of C. cyanea from a xerophytic habitat in Mexico indicates the wide adaptability of the genus. Kost (1984) identified that the genus Tricholoma colossum (Fr.) Qu'l. forms large basidiomata, but differs from Tricholoma staude (Fr.) and its hemiangiocarpic development resulting in an annulate stipe, together with differences in the subhymenial layer, basidia and by the presence of true cheilocystidia and pleurocystidia. Furthermore, it lacks in clamp connections.

Inyod et al. (2017) indicated that differentiation of morphological characteristics of five isolates of Macrocybe crassa had been very difficult (DOA, DOA1, 4, 7 and 10) with that of M. gigantea or Tricholoma giganteum. However, they can be partially differentiated by the shape of stipes, which are cylindrical and swollen at the base. Presence of clavate basidia and basidiomata are almost similar in M. crassa (Berk.) Pegler \& Lodge or T. crassum (Berk.), which completely 
differed from M. gigantean (Massee). On the other hand, molecular analyses of all the five isolates revealed 57-99 percent similarity with $T$. giganteum, may be due to the limited ITS rDNA sequences of $M$. crassa available in the biological sequence data bases.

Macrocybe has been treated in Tricholoma until Pegler et al. (1998), who segregated Macrocybe from Tricholoma and ranked it to a genus status using morphological and molecular characteristics. Species of Macrocybe are saprophytic, large with clamped hyphae, while those of Tricholoma possess clampless hyphae and are obligatory ectomycorrhizal. Molecular analysis based on the larger sub-unit of rDNA could separate Macrocybe from Tricholoma which shows a close relationship with $C$. indica and $C$. gambosa (Pegler et al., 1998; Razaq et al., 2016). In this study, the objective was framed to identify the morphology and yield performance of milky mushroom isolates for both the wild and cultivars.

\section{MATERIALS AND METHODS Collection of cultures}

The wild strains of milky mushroom viz., CBE-TNAU-1513 to 1525, 1603, 1604 and 1701 were collected from different habitats at various geographical locations in Tamil Nadu during 2014-2017. The collected isolates were pure cultured and the passport data for individual isolate was prepared based on their habit, habitat and morphological features. Along with these strains, the cultivated milky mushroom Calocybe indica var. APK2 (released from TNAU) and 8 different cultures obtained through AICRP on mushroom from the ICAR-Directorate of Mushroom Research, Solan, Himachal Pradesh were used in the experiments conducted as per objectives.

\section{In vitro testing of growth}

In vitro studies were carried out to study the growth characters of the strains. To $100 \mathrm{~mL}$ of sterilized PDA medium, $0.3 \mathrm{~mL}$ of $500 \mathrm{ppm}$ streptomycin sulphate was added and thoroughly mixed. The medium was cooled to $45^{\circ} \mathrm{C}$ and poured into sterile Petri plates. After solidification $9 \mathrm{~mm}$ mycelial discs taken from an actively growing $7 \mathrm{~d}$ old culture were aseptically placed at the centre of the Petri dishes. The dishes were incubated at 30 $\pm 2^{\circ} \mathrm{C}$. The growth parameters like colony diameter, colony colour and morphology were recorded at regular intervals. The changes observed in the Petri dishes were recorded and photographed.

\section{Cultural and agronomic traits}

The cultures of 25 isolates including $C$. indica var. APK2 were inoculated on sorghum spawn. After complete colonization, they were used for bed preparation. In order to verify the yield and yield attributing characters of milky mushroom isolates comparison with the ruling var. APK2, poly house trails were conducted at Mushroom Research Laboratory, Tamil Nadu Agricultural University, Coimbatore. The mycelial cultures of isolates viz., CBE-TNAU-1513, 1517, 1521, 1522, 1523 were inoculated on sorghum grain spawn. After complete colonization, mushroom beds were prepared following "polybag method" described by Baskaran et al. (1978) and Krishnamoorthy (2003). Polythene bags of $60 \times 30 \mathrm{~cm}$ size and $100 \mathrm{G}$ thickness were used for bed preparation and $500 \mathrm{~g}$ of paddy straw on dry weight basis was used. Layer spawning was followed using two per cent spawn rate. The beds were incubated at room temperature $\left(30 \pm 2^{\circ} \mathrm{C}\right)$ for spawn running and cropping. In the cropping rooms $80-90$ per cent relative humidity was maintained. After 15 days, when the beds were fully colonized, they were cut into two equal halves and steamed casing soil (black loam soil, pH 8.3) was applied uniformly, up to $2 \mathrm{~cm}$ over the spawn run beds. The moisture level at the casing surface was maintained by regular water spray. The bags were further incubated in a partially sunken poly house roofed with blue coloured high density polythene sheet. The observations on days for spawn run (DFSR), days for pinhead formation (DFPF), number of buttons formed per bed (NBF), number of buttons harvested per bed (NBH) after 30, 37 and $45 \mathrm{~d}$ and morphological characters like stipe length and breadth; pileus diameter and thickness of test strains were recorded and compared with the ruling variety APK2. Total yield per $180 \mathrm{~g}$ of paddy straw substrate, average weight of the individual sporophore and bio-efficiency were also recorded as given below:

$$
\begin{aligned}
& \text { Biological Fresh weight of mushrooms } \\
& \text { efficiency }=\frac{\text { harvested } / \text { bed }}{\text { Dry used of the subtrate }} \times 100 \\
& \text { (\%) used / bed }
\end{aligned}
$$




\section{Microscopic observations of morphometric characters}

Microscopic observations on morphometric characters for selected milky mushroom isolates viz., CBE-TNAU-1519, 1523, 1701 were made and compared with the existing var. APK2 by placing a drop of the $\mathrm{KOH}$ or Congo red staining solution (one $\mathrm{g}$ in $100 \mathrm{~mL}$ distilled water) directly, on the tissue surface of gills and hymenial layer. Observation on immediate and subsequent (3-5 min.) colour changes (Largent et al., 1977) were recorded. The observation on the diameter of hyphae, basidiophore, basidiospore and cystidia were also made with the help of image analyzer (N-400T, Optika, Italy).

Table 1. In vitro assessment of colony morphology

\begin{tabular}{|c|c|c|c|c|c|}
\hline \multirow[t]{2}{*}{ Isolates } & \multicolumn{3}{|c|}{ Radial growth $(\mathrm{mm})$} & \multirow[t]{2}{*}{ DTCP } & \multirow[t]{2}{*}{ Colony morphology on PDA } \\
\hline & $3 d$ & $5 d$ & $7 d$ & & \\
\hline APK2 & $45.5^{\mathrm{a}}$ & $86.0^{\mathrm{a}}$ & $90.0^{\mathrm{a}}$ & $7.3^{\mathrm{a}}$ & $\begin{array}{l}\text { Pure white, thick cottony } \\
\text { growth, smooth margin }\end{array}$ \\
\hline $\mathrm{Cl}-13-02$ & $32.6^{f}$ & $79.5^{\mathrm{b}}$ & $89.3^{a}$ & $8.6^{\mathrm{a}}$ & $\begin{array}{l}\text { White thick cottony, aerial, } \\
\text { smooth margin }\end{array}$ \\
\hline $\mathrm{Cl}-13-04$ & $28.6^{\mathrm{g}}$ & $65.1^{d}$ & $85.4^{b}$ & $9.3^{\mathrm{b}}$ & Thick cottony with smooth margin \\
\hline $\mathrm{Cl}-13-06$ & $29.8^{\mathrm{g}}$ & $61.3^{f}$ & $84.3^{b}$ & $9.6^{\mathrm{b}}$ & Creamy white, cottony aerial growth \\
\hline $\mathrm{Cl}-14-02$ & $18.6^{i}$ & $61.2^{\mathrm{e}}$ & $78.1^{d}$ & $10.6^{\mathrm{bc}}$ & $\begin{array}{l}\text { White radiating colony with } \\
\text { wavy margin }\end{array}$ \\
\hline $\mathrm{Cl}-14-03$ & $8.6^{k}$ & $41.6^{\mathrm{g}}$ & $67.3^{\mathrm{e}}$ & $11.0^{\mathrm{bc}}$ & Creamy white turns to dull white \\
\hline $\mathrm{Cl}-14-04$ & $22.3^{i}$ & $36.1^{\mathrm{h}}$ & $63.1^{f}$ & $13.1^{c}$ & Pure white sectoring upward growth \\
\hline Cl-14-06 & $28.6^{\mathrm{g}}$ & $64.2^{\text {de }}$ & $86.5^{\mathrm{ab}}$ & $9.0^{\mathrm{b}}$ & Thick cottony, smooth margins \\
\hline CBE-TNAU-1513 & $36.6^{d}$ & $79.1^{\mathrm{b}}$ & $89.0^{\mathrm{a}}$ & $8.6^{\mathrm{a}}$ & Pure white with wavy margins \\
\hline CBE-TNAU-1514 & $26.3^{\mathrm{gh}}$ & $70.0^{\text {cd }}$ & $88.4^{\mathrm{a}}$ & $9.6^{\mathrm{b}}$ & White, aerial, thick cottony \\
\hline CBE-TNAU-1515 & $39.3^{c}$ & $74.3^{c}$ & $84.1^{b}$ & $9.1^{\mathrm{b}}$ & Milky white, thick cottony \\
\hline CBE-TNAU-1516 & $38.3^{c}$ & $72.1^{c}$ & $85.1^{b}$ & $8.1^{\mathrm{a}}$ & Thin cottony with smooth margin \\
\hline CBE-TNAU-1517 & $37.6^{c}$ & $74.4^{c}$ & $86.1^{\mathrm{ab}}$ & $8.3^{\mathrm{a}}$ & Thin cottony, aerial mycelium \\
\hline CBE-TNAU-1518 & $35.3^{e}$ & $68.1^{\mathrm{d}}$ & $79.4^{\text {cd }}$ & $8.0^{\mathrm{a}}$ & Creamy white, aerial mycelium \\
\hline CBE-TNAU-1519 & $42.6^{\mathrm{b}}$ & $78.3^{b}$ & $88.5^{a}$ & $8.6^{a}$ & $\begin{array}{l}\text { Slightly yellowish with } \\
\text { aggregated mycelium }\end{array}$ \\
\hline CBE-TNAU-1520 & $25.3^{h}$ & $68.5^{d}$ & $83.8^{b}$ & $10.5^{\mathrm{bc}}$ & $\begin{array}{l}\text { Creamy white, aerial mycelium, } \\
\text { radiating growth }\end{array}$ \\
\hline CBE-TNAU-1521 & $33.3^{\text {ef }}$ & $67.4^{d}$ & $79.0^{d}$ & $9.0^{\mathrm{ab}}$ & $\begin{array}{l}\text { White, aerial growth, sparsely } \\
\text { aggregated }\end{array}$ \\
\hline CBE-TNAU-1522 & $29.6^{\mathrm{g}}$ & $67.2^{\mathrm{d}}$ & $79.4^{\mathrm{cd}}$ & $9.6^{\mathrm{ab}}$ & Thin cottony, aerial mycelium \\
\hline CBE-TNAU-1523 & $46.6^{\mathrm{a}}$ & $83.1^{\mathrm{a}}$ & $90.0^{\mathrm{a}}$ & $7.3^{\mathrm{a}}$ & $\begin{array}{l}\text { Pure white, silk thread like, } \\
\text { quickly aggregating }\end{array}$ \\
\hline CBE-TNAU-1524 & $27.3^{\mathrm{gh}}$ & $81.2^{\mathrm{ab}}$ & $89.5^{\mathrm{a}}$ & $8.6^{\mathrm{a}}$ & Thick cottony with smooth margin \\
\hline CBE-TNAU-1525 & $15.0^{j}$ & $59.0^{f}$ & $83.1^{b}$ & $10.4^{\mathrm{bc}}$ & Thick cottony, upwards, smooth margin \\
\hline CBE-TNAU-1526 & $14.6^{j}$ & $61.3^{\mathrm{e}}$ & $79.6^{c}$ & $9.0^{\mathrm{b}}$ & White cottony, thin mycelium \\
\hline CBE-TNAU-1603 & $45.2^{\mathrm{a}}$ & $82.2^{\mathrm{ab}}$ & $90.0^{\mathrm{a}}$ & $7.3^{\mathrm{a}}$ & Thin cottony growth with smooth margin \\
\hline CBE-TNAU-1604 & $28.3^{\mathrm{g}}$ & $59.5^{f}$ & $81.2^{c}$ & $10.1^{\mathrm{b}}$ & Radiating colony with wavy margin \\
\hline CBE-TNAU-1701 & $37.6^{c}$ & $63.2^{\mathrm{e}}$ & $82.5^{c}$ & $9.3^{\mathrm{b}}$ & $\begin{array}{l}\text { Dull white, sparsely aggregated } \\
\text { mycelium }\end{array}$ \\
\hline C. $D(P=0.05)$ & 1.42 & 3.10 & 3.40 & 1.58 & \\
\hline
\end{tabular}

DTCP - Days taken to cover $90 \mathrm{~mm}$ Petri dish; DAI-Days after inoculation Mean of 3 replications, Means followed by a common letter are not significantly different at $\mathrm{P}=0.05$ by one way ANOVA. 


\section{RESULTS AND DISCUSSION}

In vitro cultural and morphological characters

Colony characters of all the 25 isolates of milky mushroom grown on PDA medium were recorded. Among the isolates, CBE- TNAU-1523, APK2 and 1603 were found to be fast growing covering the maximum radial growth of $90 \mathrm{~mm}$ in Petri dish within 7 days (Figure 1). However, the linear growth of the isolates $\mathrm{Cl}-13-02, \mathrm{Cl}-14-$ 06, CBE-TNAU-1513, 1514, 1517 and 1519 were also found to be statistically on par covering approximately $86 \mathrm{~mm}$ of growth during the same

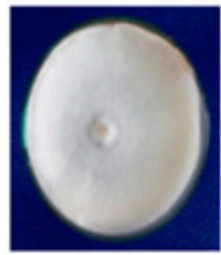

APK2

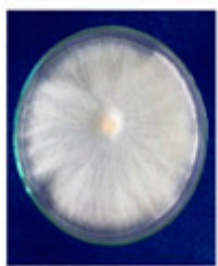

CI-14-03

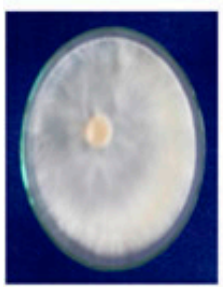

CBE-TNAU-1515

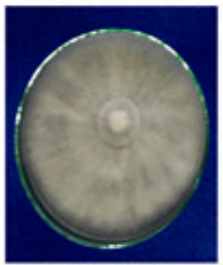

CBE-TNAU-1520

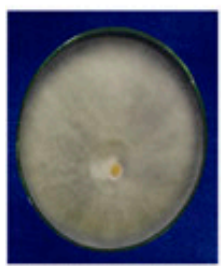

CBE-TNAU-1525

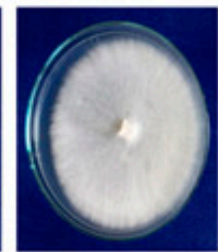

CI-13-02

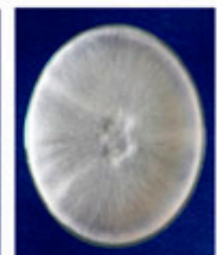

CI-14-04

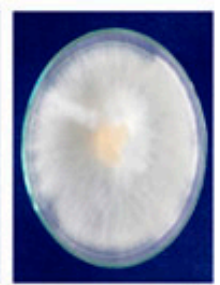

CBE-TNAU-1516

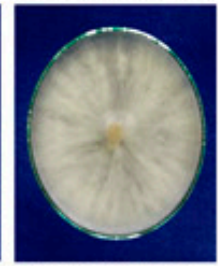

CBE-TNAU-152

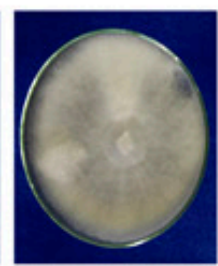

CBE-TNAU-1526

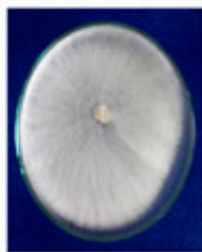

CI-13-04

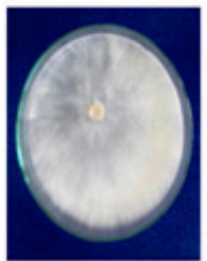

CI-14-06

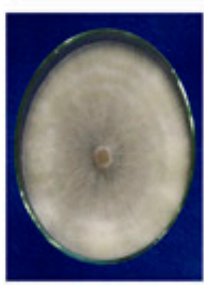

CBE-TNAU-1517

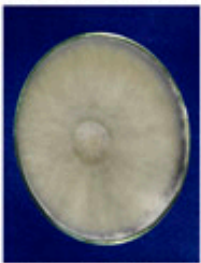

CBE-TNAU-1522

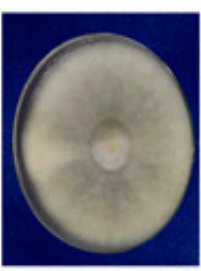

CBE-TNAU-1603

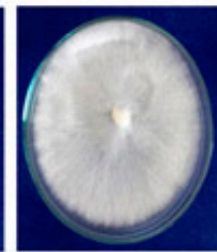

CI-13-06

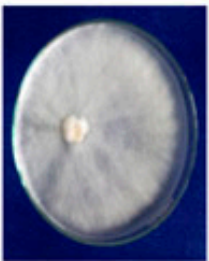

CBE-TNAU-1513

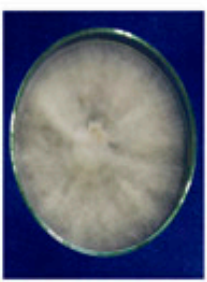

CBE-TNAU-1518

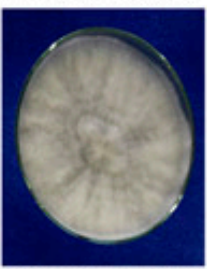

CBE-TNAU-1523

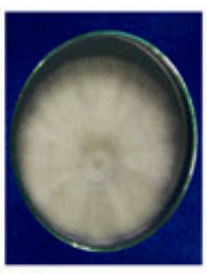

CBE-TNAU-1604

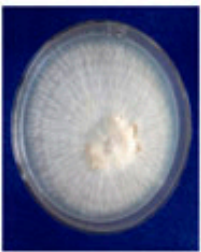

CI-14-02

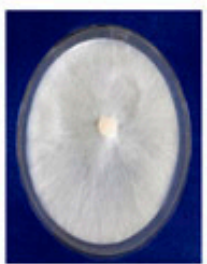

CBE-TNAU-1514

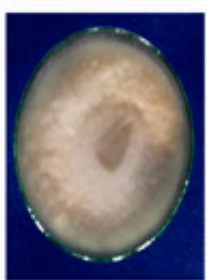

CBE-TNAU-1519

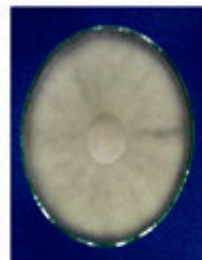

CBE-TNAU-1524

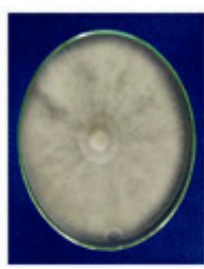

CBE-TNAU-1701

Fig. 1. Cultural characters of milky mushroom isolates on PDA medium. White thick cottony growth with more or less smooth margin was observed in APK2, Cl-13-02, C1-13-04, Cl-14-06, CBE-TNAU-1514, 1515 and 1517. Thick cottony slightly yellowish colony growth was prominent in cases of CBE-TNAU-1522 and 1524. Silk thread like meandering mycelium was observed with respect to $\mathrm{Cl}-14-04, \mathrm{CBE}-\mathrm{TNAU}-1519,1521$ and 1523. The isolates viz., CBE- TNAU-1523, CBE-TNAU-1603 and APK2 isolates were covering the maximum radial growth of $90 \mathrm{~mm}$ in Petri dish within 7 days. 


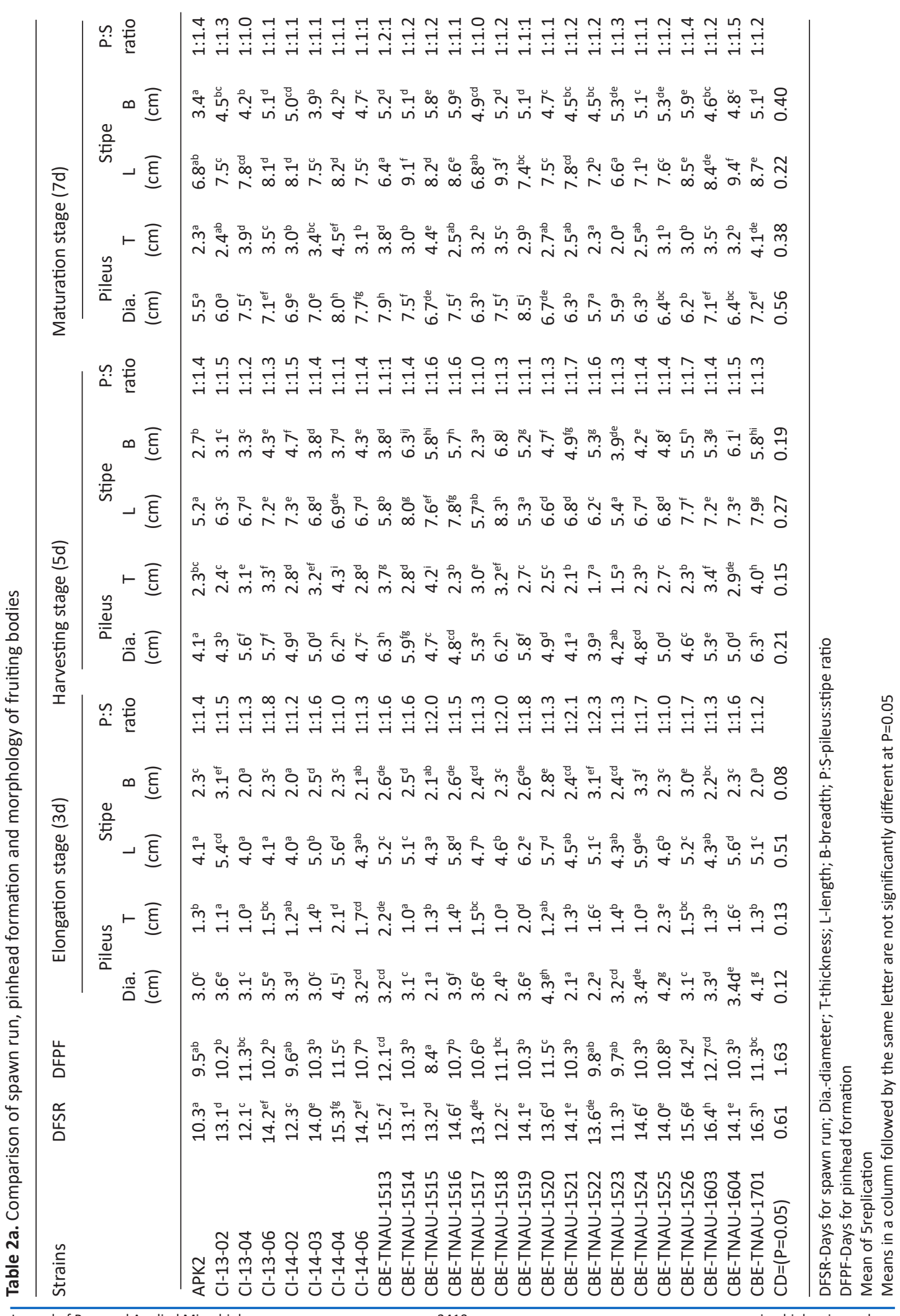




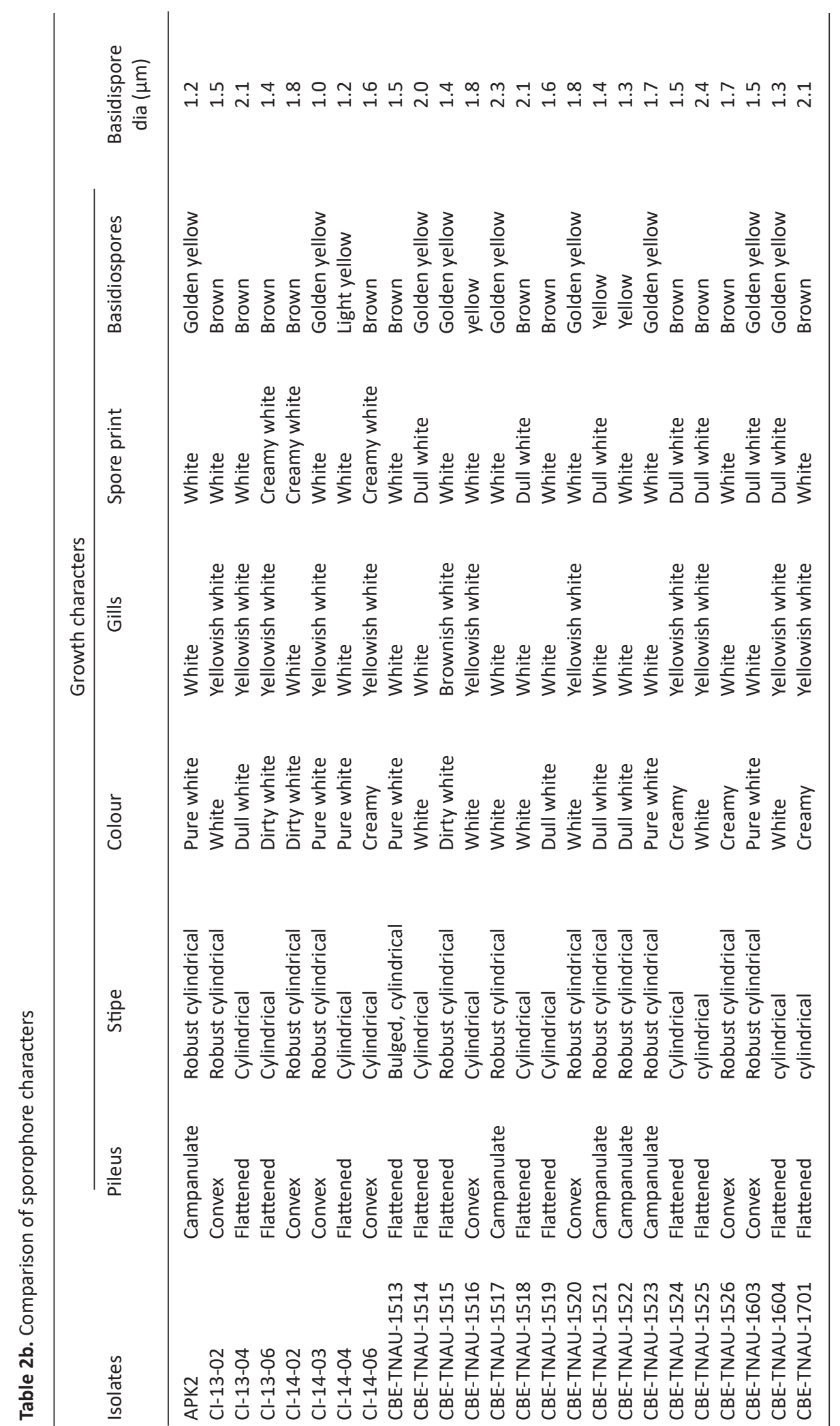




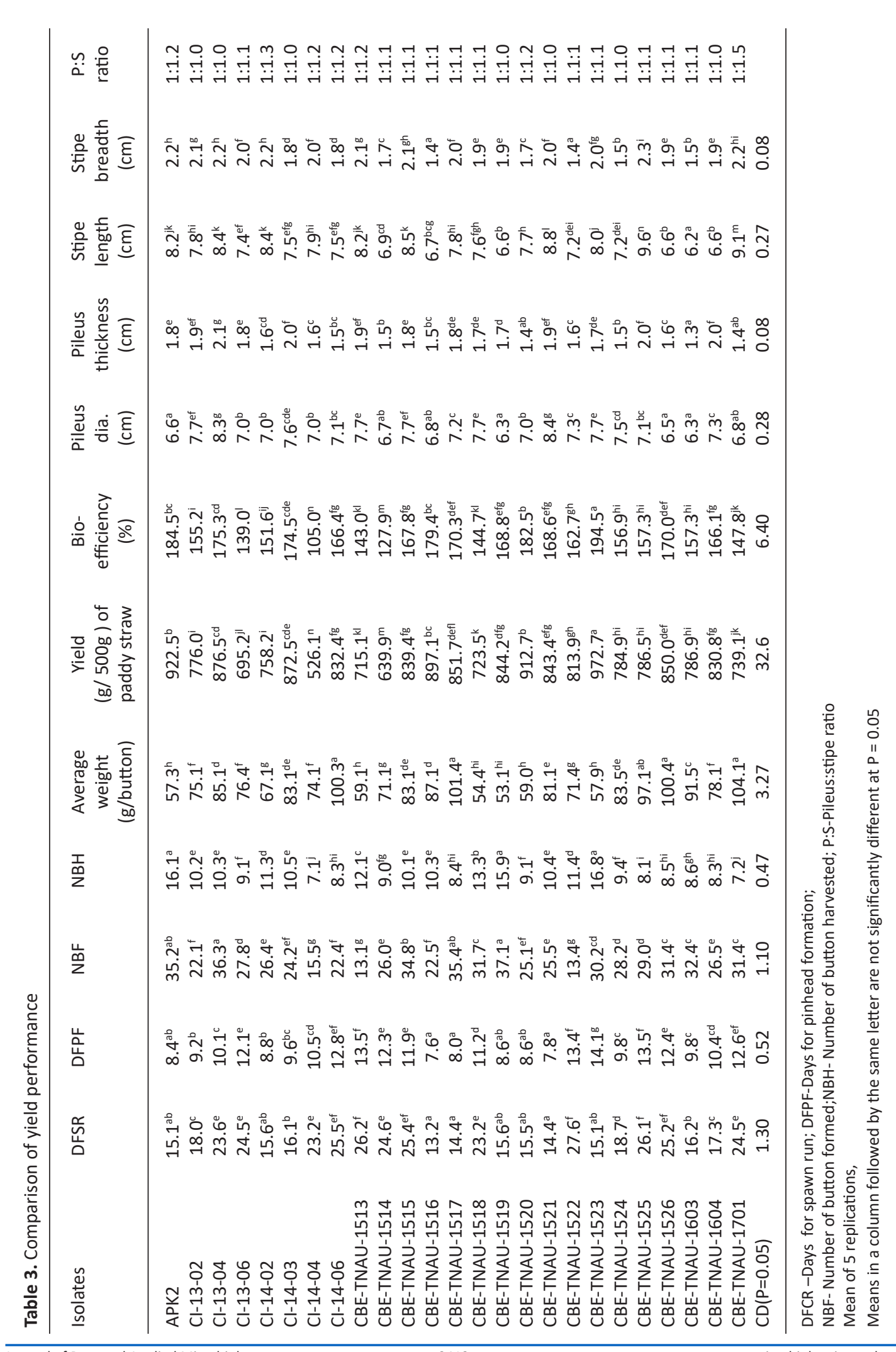




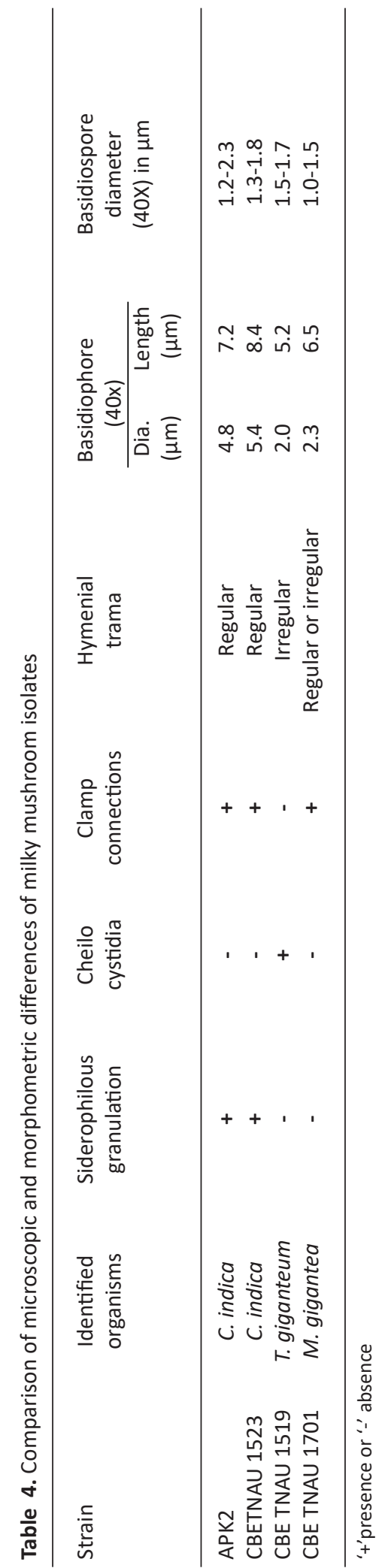

period of observation. The isolate $\mathrm{Cl}-14-04$ was found to be slow growing, which covered only $63.1 \mathrm{~mm}$ over a period of $7 \mathrm{~d}$ (Table 1). White thick cottony growth with more or less smooth margin was characteristically observed with respect to the isolates $\mathrm{APK} 2, \mathrm{Cl}-13-02, \mathrm{C} 1-13-04$, Cl-14-06, CBE-TNAU-1514, 1515 and 1517. Thick cottony slightly yellowish colony growth was prominent in cases of CBE-TNAU-1522 and 1524. Silk thread like meandering mycelium was found to be quickly aggregated either at the centre or in the margin of Petri dishes during the mycelial morphogenesis of Cl-14-04, CBE-TNAU-1519, 1521 and 1523. Clamp connections in the mycelium were also frequently observed in the isolates viz., APK2, CBE-TNAU-1513, 1517, 1521, 1522 and 1523; whereas, in all other isolates clamp connections were observed occasionally. Such kind of varied growth in the culture for Calocybe, Macrocybe and Tricholoma has been indicated by Purkaysatha and Chandra (1974), Kalpana et al. (2005), Thiribhuvanamala (2011), Arun Kumar and Acharya (2014). Pegler (1983) also indicated colony colour variation of Calocybe spp. Kost (1984) indicated that clamp connections were absent in Tricholoma spp. Krishnamoorthy et al. (1998) reported that the time required for maximum mycelial growth of $C$. indica in culture media like potato dextrose agar or malt extract agar was 8 to 10 days. Suman et al. (2018) reported that Macrocybe gigantea and Calocybe indica had produced fluffy and extensive aerial growth, which gave the appearance of cotton wool on PDA and MEA media.

Screening of isolates based on spawn run and fruiting body morphology

In order to find out the best performing wild isolate with respect to spawn run and fruiting body size, a preliminary trial was conducted using $1800 \mathrm{~mL}$ polypropylene bottles. The observations recorded with respect to spawn run and morphometric characters viz., days for spawn run (DFSR), days for pin head formation (DFPF), pileus and stipe measurements including the pileus: stipe ratio for all the strains tested are presented in Tables 3a, b and Figure 2a, b. Observations on DFSR showed that, complete spawn run was faster in APK2 (10.3 d). However, mycelial impregnation in the casing soil was comparatively quick with the isolate CBE-TNAU-1515, which was reflected 
in early pinning with this isolate (8.4d). The results also showed variations with respect to DFSR (ranged from 10.3 to 16.4) and DFPF (ranged from 8.4 to 12.7 ) (Table $2 a$ and Figure $2 a, b$ ). The strains viz., CBE-TNAU-1517, 1521, 1522, 1523 and APK2 possessed companulate robust sporophores, having cylindrical stipe, moderately bulged at the base. Tin these cases the pileus margin was found to be incurved. The pileus:stipe ratio at harvesting maturity ( $5 \mathrm{~d}$ after pinhead formation) was found to be narrow in Cl-14-04, CBE-TNAU-1513, CBETNAU-1519 (1:1.1), while it was found to be 1:1.4 in the cultivar. APK2 and 1:1.3 in case of CBETNAU-1523. In case of all other isolates, much variations existed with respect to pileus: stipe ratio (Table 2a). Although P:S ratio was observed to be narrower in some of the isolates, the pileus showed convex or expanded pileus with flattened margin (Table $2 \mathrm{~b}$ ). In such cases, the pileus thickness was more at the centre, which decreased towards the margin. Compact fruiting bodies with incurved pileus margin were conspicuously noticed in five of the $C$. indica isolates viz., CBE-TNAU-1517, 1521, 1522, 1523 and APK2. The colour of gills and spore print showed wide variations of white shade including creamy white, dull white and white with yellow tinge. The basidiospores were mostly brown or golden yellow and the diameter of the basidiospores ranged from 1.0 to $2.4 \mu \mathrm{m}$ (Table $2 \mathrm{~b}$ and Figure $2 \mathrm{a}, \mathrm{b}$ ). Pandey and Tewari (2003) also made comparison studies on the morphological characters and fruiting
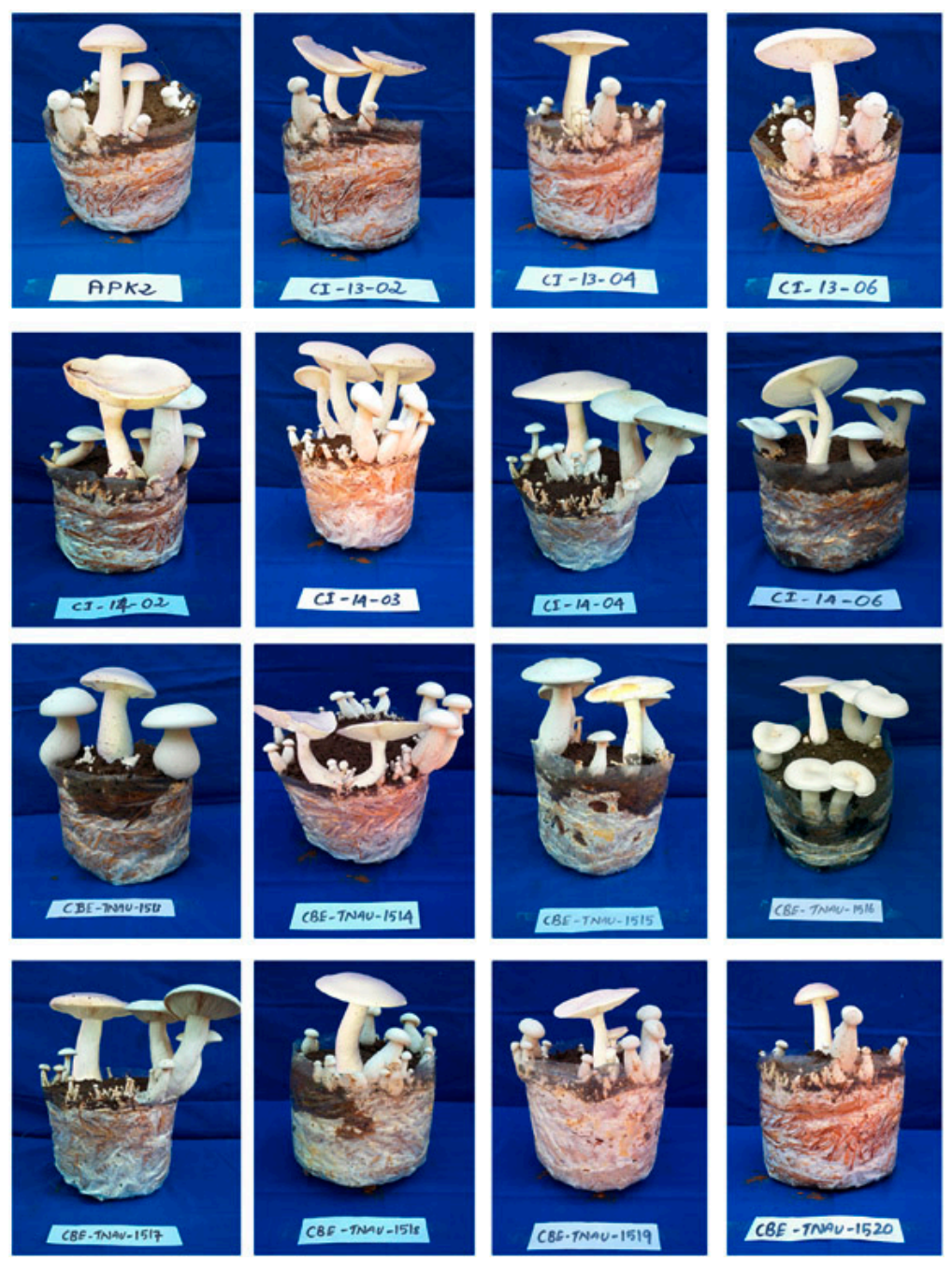

Journal of Pure and Applied Microbiology

2414

www.microbiologyjournal.org 

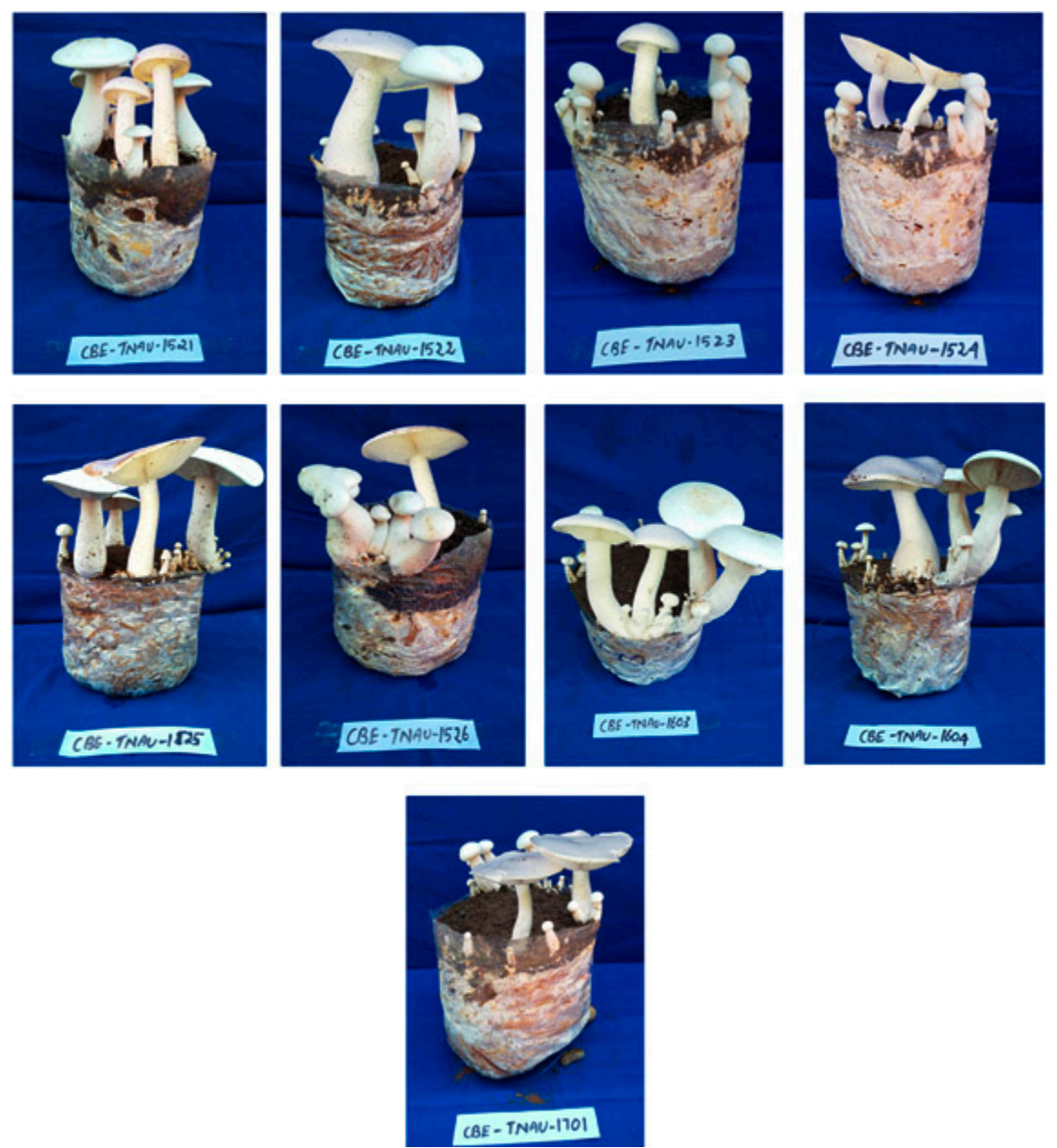

Fig. 2a, b. Morphological evaluation of milky mushroom isolates

body production of Tricholoma giganteum and C. indica and concluded that, both the species had a striking resemblance. The only difference noticed could be a very shallow stipe at the base and solitary appearance in T. giganteum, whereas sporophores of $C$. indica were growing in clusters with a slightly larger pileus. Contrarily, in the present stud, size wise observation in ascending order indicated Calocybe, Tricholoma and Macrocybe, respectively. Razaq et al. (2016) also indicated that milky mushroom (Macrocybe gigantea) was found to be fairly fleshy with large cap $(7-8 \mathrm{~cm})$ fibrous stipe. In a similar study Singh et al. (2017) described about the morphological characters of Calocybe sp. They have reported that pileus size was found to be between 4.5 and 6.16 $\mathrm{cm}$ in diameter and produced convex to flattened fruiting bodies with appressed scales. Further they have observed that the surface of the stipe found to be dry and attached centrally, cylindrical at the apex with sub- bulbous base.

Screening the isolates based on yield performance Gyurko (1982) indicated that the wild strains are usually vigorous, since nature is selecting only the vigorous to survive. It is not certain in all cases that, the wild strains are the best suited for our needs, because the aim of nature is different from that of human being. It is the matter of survival in nature and plenty of time is available for the organism to fit its level best to thrive. However, man wants to grow in a short time as much quantity of mushrooms 
as possible. Kalpana et al. (2005) studied and compared the yield and flushing patterns of milky mushroom wild isolates with the cultivar APK2 and recorded the maximum yield and more number of buttons in WC2 wild isolate followed by WC6. During the present investigation, experiments were conducted to evaluate the performance of different strains, significantly increased yield was obtained with the strain CBE-TNAU-1523 (972 g per bed with 194.5 per cent bio efficiency). The number of buttons formed and harvested was 30.2 and 16.8 , respectively. The average weight of individual mushroom in case of CBE-TNAU-1523 was $57.9 \mathrm{~g}$. The second best isolate was found to be APK2, which recorded $922.5 \mathrm{~g}$ of yield per bed (184.5 per cent bio-efficiency) with average weight of $57.3 \mathrm{~g}$ per mushroom. The var. APK2 produced a total number of 35.2 buttons, of which, only 16.1 attained the harvesting maturity. The performance of CBE-TNAU-1523 was also found to be statistically on par with that of APK2 (Table 3). Less number of buttons (10.2, 9.1, 7.1 and 7.2, respectively) and comparatively poor yields (776, 695, 526 and $739 \mathrm{~g}$ per bed, respectively) were noticed with the strains $\mathrm{Cl}-13-02, \mathrm{Cl}-13-06, \mathrm{Cl}-14-$ 04 and CBE-TNAU-1701. Gyurko (1982) indicated
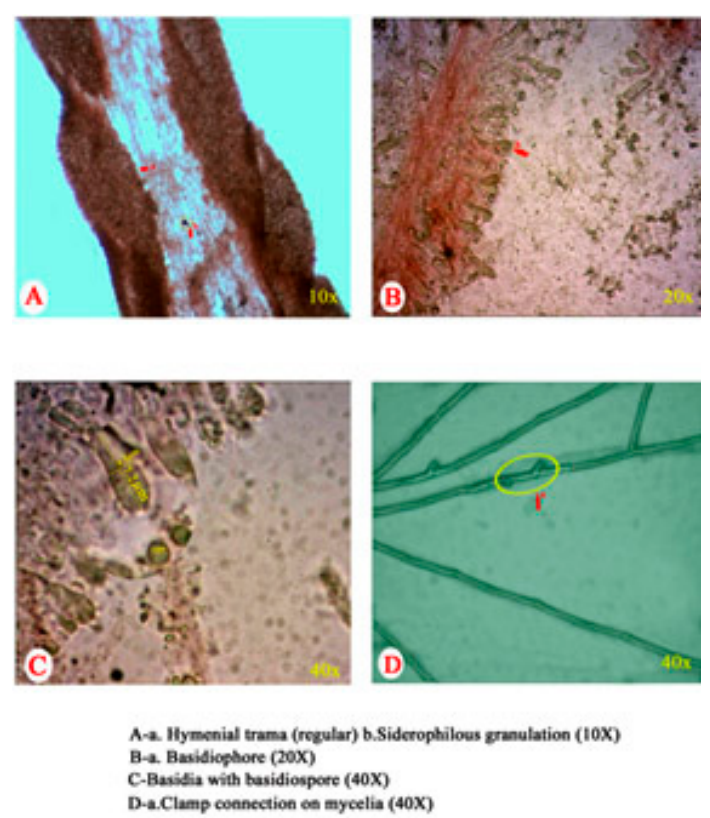

Fig. 3a. Microscopic observation of Calocybe indica (var.APK2) that the wild strains are usually vigorous, since nature is selecting only the vigorous to survive. It is not certain in all cases that, the wild strains are the best suited for our needs, because the aim of nature is different from that of human being. It is the matter of survival in nature and plenty of time is available for the organism to fit its level best to thrive. However, man wants to grow in a short time as much quantity of mushrooms as possible. Kalpana et al. (2005) studied and compared the yield and flushing patterns of milky mushroom wild isolates with the cultivar APK2 and recorded the maximum yield and more number of buttons in WC2 wild isolate followed by WC6.

Krishnamoorthy et al. (2000) and Krishnamoorthy and Muthusamy (1997) reported that the $C$. indica var. APK2 had a short crop cycle ( $7 \sim 8 \mathrm{wk})$ and produced good yield (140 $\mathrm{kg}$ fresh mushroom/100 kg dry paddy straw as substrate) with a biological efficiency of 140 per cent. Likewise, Tandon and Sharma (2006) and Bhatt et al. (2007) reported that wheat straw and paddy straw showed minimum days for spawn run and recorded good yield with higher biological efficiency. Sharma and Kumar (2008) evaluated the yield potential on different strains of Calocybe indica viz., APK-2, $\mathrm{Cl}-1, \mathrm{Cl}-3, \mathrm{Cl}-6$ and $\mathrm{Cl}-7$ and
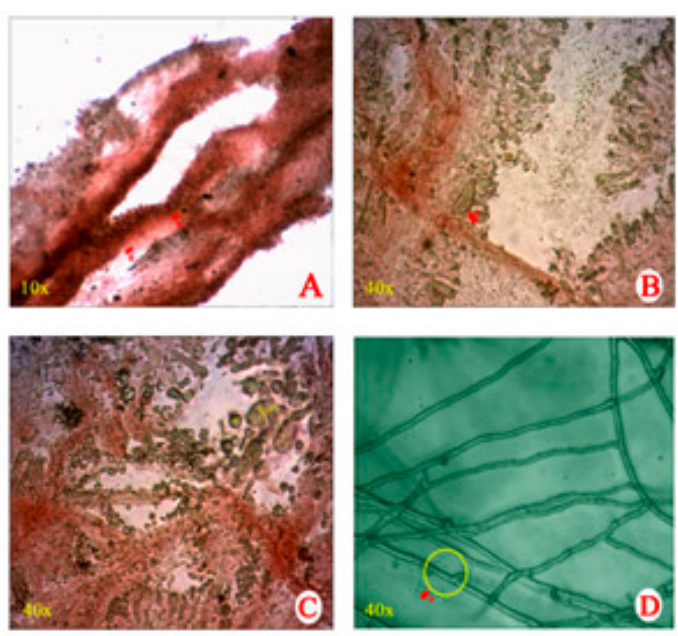

A-a. Hymenial trama (regular) b.Siderophilous granulation (10X) B-a. Basidicophore (20X) C-Basidia with basidiospore (40X)

D-a.Clamp eonnection on myeelia (40X)

Fig. 3b. Microscopic observation of Calocybe indica (CBE-TNAU-1523) 
recorded maximum biological efficiency with $\mathrm{Cl}-6$. They also reported that the highest average weight of fruiting bodies was obtained with APK2, which was found to be significantly higher than $\mathrm{Cl}-6$, $\mathrm{Cl}-7$ and $\mathrm{Cl}-1$. A similar study was also conducted by Dhakad et al. (2015), who evaluated the yield potential of different strains of Calocybe indica viz., $\mathrm{Cl}-4, \mathrm{Cl}-13, \mathrm{Cl}-14, \mathrm{Cl}-15$ and $\mathrm{Cl}-18$ with wheat straw finally suggested that the strain $\mathrm{Cl}-14$ performed better with a yield potential of $811.3 \mathrm{~g} \mathrm{~kg}^{-1}$ of dry wheat straw. When compared to this reports, it can be strongly concluded that, CBE-TNAU-1523 and APK2 could be the best strains for cultivation with paddy straw as substrate.

\section{Microscopic observation}

Calocybe indica has been placed under Calocybe - Sect. I. Calocybe (Guttatae) (Fr.) Sing. (Pegler, 1983). The hymenophoral trama was regular, but slight diversence was seen in the hymenium. The siderophileus granulation was highly present in basidia. Spores were thin walled,
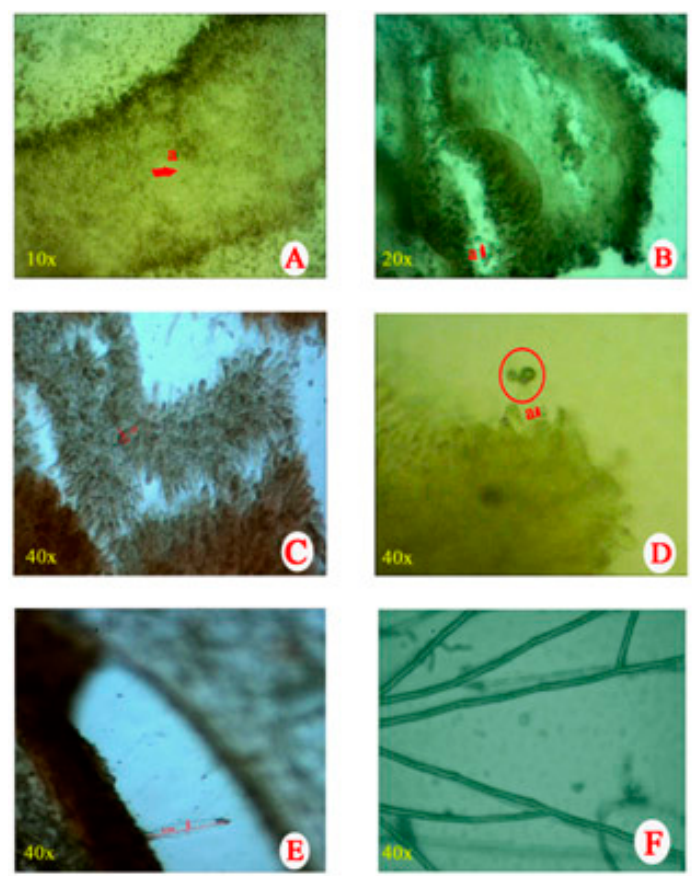

A-a.Gill components with hymenial trama (irregular) (10X) B-a.Arrangment of cheilocystidia on gills (20X) C-Basidia with basidiospore (40X) D-a.Basidia with basidiospores on sterigmata $(40 \mathrm{X})$

E-Matured cystidia (40X)
F-Mycelia without elamp connections ( $40 \mathrm{X})$

Fig. 3c. Microscopic observation of Tricholoma giganteum (Massee) (CBE-TNAU-1519) hyaline and creamy yellow to brown. Cystidia were not highly differentiated, although several cylindrical units with granular contents were observed. Clamp connections were also present in the hypha. The sporocarps were highly campanulate and robust. The genus has been classified under, Tribus lyophylleae, Fa: Tricholomataceae and Or: Agaricales (Singer, 1961). Macrocybe has been treated in Tricholoma, until it was segregated and ranked it to a separate genus using morphological and molecular characterization (Pegler et al., 1998 and Razaq et al., 2016). Macrocybe is also known as a tricholomatoid species with fleshy, cream to grayish, convex, umbonate to depressed basidiomata. However, Siderophilous granulation and cheilocystidia were absent in this species; whereas in Tricholoma, the cheilocystidia in basidia were highly prominent. This species possessed clamp connections in the hyphae.

Microscopic observations of mycelial characters and basidiospores of $C$. indica, T. giganteum and $M$. gigantea are presented in Table 4. The clamp connections and siderophilous granulation were noticed in $C$. indica (APK2 variety and CBE-TNAU-1523) and whereas, clamp connections and siderophilous granulation were absent in T. giganteum (CBE-TNAU-1519). M.
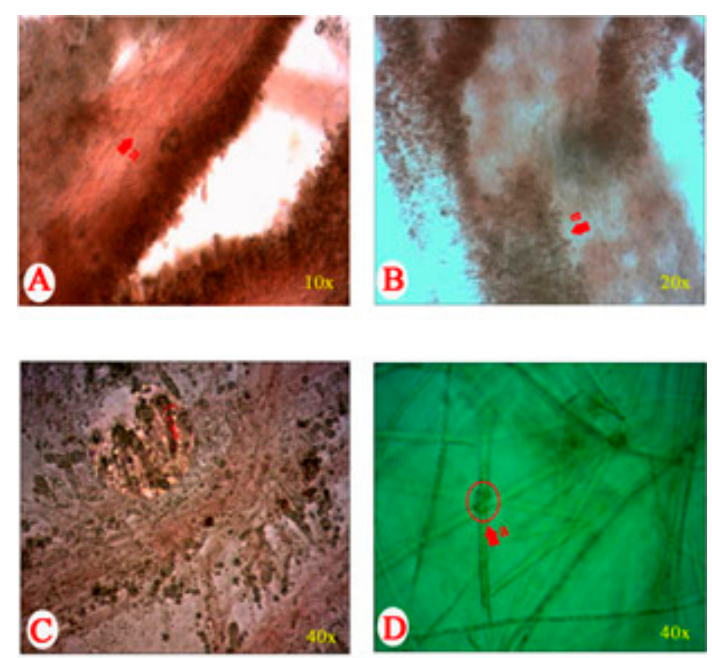

B-a. Basidiephore (20X)
C-Basidia with basidiospore ( $40 \mathrm{X})$
D-a.Clamp connection on mycellia (40X)

Fig. 3d. Microscopic observation of Macrocybe gigantea (Massee) (CBE-TNAU-1701) 
gigantea (CBE-TNAU-1704) lacks siderophilous granulation in the basidia and cheilocystidia. The matured cheilocystidia were identified in $T$. giganteum (CBE-TNAU-1519) while, they were not seen in C. indica and M. gigantea isolates (Fig. 3a-3d) (Table 4).

\section{CONCLUSION}

The results clearly indicated that $C$.indica isolates always possessed companulate to highly companulate pileus with incurved margin; whereas, $T$. giganteum and $M$. gigantea could be differentiated by flattened to highly flattened cap. The stipe portion of C.indica isolates was moderately bulbous at the base and the stipe diameter was found to be gradually reduced towards the tip; whereas, in case of $T$. giganteum the pileus was highly bulbous at the base and reduced sharply, in width towards the apex. In case of $M$. gigantea, the stipe was stout and more or less cylindrical from base apex. Although P: S ratio was observed to be narrower in some of the isolates, the pileus showed convex to expanded margin with flattened margin. This kind of fruiting bodies with bigger size may face packaging and marketing problem. In general consumer preference is always for medium sized mushrooms weighing 40-45 g per button, having a narrow pileus and stipe ratio. Production of uniform fruiting bodies having defined pileus: stipe ratio is another challenge in milky mushroom cultivation. Further research will lead to identification of the gene activity and gene alteration through genome editing techniques to reduce the mushroom size and to improve the pileus and stipe ratio of milky mushroom.

\section{ACKNOWLEDGEMENTS}

None.

\section{CONFLICTS OF INTEREST}

The authors declare that there is no conflict of interest.

\section{AUTHOR'S CONTRIBUTION}

All authors listed have made a substantial, direct and intellectual contribution to the work, and approved it for publication.

\section{FUNDING}

None.

\section{DATA AVAILABILITY}

All datasets generated or analyzed during this study are included in the manuscript.

\section{ETHICS STATEMENT}

This article does not contain any studies with human participants or animals performed by any of the authors.

\section{REFERNCES}

1. Alam, N., R. Amin, A. Khan, I. Ara, M.J. Shim, M.W. Lee and T.S. Lee. Nutritional analysis of cultivated mushrooms in Bangladesh-Pleurotus ostreatus, Pleurotus sajor-caju, Pleurotus florida and Calocybe indica. Mycobiology, 2008; 36(4): 228-232. https:// doi.org/10.4489/MYCO.2008.36.4.228

2. Baskaran, T.L., K. Sivaprakasam and T.K. Kandasamy. Compact bag method: A new method of increasing the yield of Pleurotus sajor-caju. Indian Journal of Mushrooms, 1978; 4: 10-12.

3. Bhatt, P., K.P.S. Kushwaha and R.P. Singh. Evaluation of different substrates and casing mixtures for production of Calocybe indica. Indian Phytopathology, 2007; 60: 128-130.

4. Boa, E. Wild edible fungi: A global overview of their use and importance to people. Food and Agriculture Organization of the United Nations, Rome.FAO Technical Paper Non-Wood Forest Products No. 17, 2004.

5. Chakraborty, U and S.R. Sikdar. Intergeneric protoplast fusion between Calocybe indica (milky mushroom) and Pleurotus florida aids in the qualitative and quantitative improvement of sporophore of the milky mushroom. World Journal of Microbiology and Biotechnology, 2010; 26(2): 213-225. https://doi. org/10.1007/s11274-009-0162-8

6. Chang, S.T. and P.G. Miles. Mushroom biology-a new discipline. Mycologist, 1992; 6(2): 64-65. https://doi. org/10.1016/S0269-915X(09)80449-7

7. Dhakad, P.K., Ram Chandra, M.K. Yadav and Usha R. Patar. Comparative study on growth parameters and yield potential of five strains of milky mushroom (Calocybe indica). J Pure Appl Microbiol, 2015; 9(3): 2333-2337.

8. Dutta, A.K. and K.R. Acharya. Traditional and ethnomedicinal knowledge of mushrooms in West Bengal, India. Asian Journal of Pharmaceutical and Clinical Research, 2014; 7(4): 36-41.

9. Gyurko, P. Selecting new strains of the oyster mushroom (Pleurotus ostreatus). Mushroom Journal, 1982; 111: 103-105.

10. Inyod, T., S. Sassanarakit, A. Payapanon and S. Keawsompong. Morphological characteristics and molecular identification of a wild Thai isolate of the tropical mushroom Hed Taen Rad (Macrocybe 
crassa). Biodiversitas Journal of Biological Diversity, 2017; 18(1): 221-228. https://doi.org/10.13057/ biodiv/d180129

11. Kalpana, K., A.S. Krishnamoorthy and S. Nakkeeran. Exploration of the diversity of milky mushroom Calocybe indica (P\&C). In: Advances in Fungal Diversity and Host Pathogen Interaction, B.F. Rodrigues, H.N. Gour, D.J. Bhat and N. Kamat, (eds.), Goa University, Goa. India. 2005; 97-108.

12. Kost, G. Megatricholoma nov. Gen., a new agaricoid genus with Organisationsstufen the Homobasideiomycetes. Sydowia, 1984; 37: 53-74.

13. Krishnamoorthy A.S. Commercial prospects of milky mushroom (Calocybe indica) on tropical plains of India. In: Upadhyay RC, Singh SK, Rai RD (eds.). Current vistas in mushroom biology and production. Solan (HP): Mushroom Society of India. 2003; 131-135.

14. Krishnamoorthy, A.S., M.T. Muthuswamy and S. Nakkeeran. Technique for commercial production of milky mushroom Calocybe indica (P\&C). Indian Journal of Mushrooms, 2000; 18:19-23.

15. Krishnamoorthy, A.S and Muthuswamy M. Yield performance of Calocybe indica (P\&C) on different substrates. Mushroom Research, 1997; 6: 29-32.

16. Krishnamoorthy, A.S and V. Balan. A Comprehensive Review of Tropical Milky White Mushroom (Calocybe indica P\&C). Mycobiology, 2015; 43(3): 184-194. https://doi.org/10.5941/MYCO.2015.43.3.184

17. Krishnamoorthy, A.S. Studies on the cultivation of milky mushroom (Calocybe indica P\&C). Ph.D., (Ag.) Thesis. TNAU, Coimbitore, India. 1995; 222.

18. Krishnamoorthy,A.S., M. Muthusamy, T. Marimuthu, V. Narasimhan and A. Muthusankaranarayanan. APK2 milky mushroom-Extn. Bulletin, RRS, TNAU, Aruppukottai. 1998; 18.

19. Largent, D., D. Johnson and R. Watling. How to Identify Mushrooms to Genus 3: Microscopic Feature. Mad River Press, Eureka. 1977; 148.

20. Mallavadhani, U.V., A.V. Sudhakar, K.V.S. Satyanarayana, A. Mahapatra and W. Li. Chemical and analytical screening of some edible mushrooms. Food Chemistry, 2006; 95(1): 58-64. https://doi. org/10.1016/j.foodchem.2004.12.018

21. Pandey, M and R.P. Tewari. Tricholoma giganteum - A new potential species for tropical region. Current Vistas in Mushroom Biology and Production (eds.) Upadhyay, R.C., Singh, S.K. and Rai, R.D. Mushroom Society of India, Solan, 2003; 115-120.

22. Pani, B.K. Sporophore production of milky mushroom (Calocybe indica) as influenced by depth and time of casing. International Journal of Advanced Biological Research, 2012; 2(1): 168-170.

23. Pegler, D.N. The genus Lentinula (Tricholomataceae tribe Collybieae). Sydowia, 1983; 36: 227-239.

24. Pegler, D.N., D.J. Lodge and K.K. Nakasone. The pantropical genus Macrocybe gen. nov. Mycologia. 1998. 90(3): 494-504. https://doi.org/10.1080/0027 5514.1998.12026934

25. Purkayastha RP and A. Chandra. A new technique for in vitro production of Calocybe indica-an edible mushroom of India. The Mushroom Journal. 1976. 40: 112-113.

26. Purkayastha, R. P and A. Chandra. 1974. Studies on Calocybe indica, an edible mushroom of India. In Proceedings of VI European mycological Congress Avigon, France.

27. Razaq, A., R. Nawaz and A. N. Khalid. An Asian edible mushroom, Macrocybe gigantea: its distribution and ITS-rDNA based phylogeny. Mycosphere. 2016. 7(4): 525-530. https://doi.org/10.5943/mycosphere/7/4/11

28. Sharma, JP and S. Kumar. Evaluation of strains of milky mushroom (Calocybe indica) for cultivation in Jharkhand. Mushroom Research. 2008. 17(1):31-33.

29. Singer, R. New and interesting species of basidiomycetes. II. Papers of the Michigan Academy of Science, Arts and Letters. 1948; 32:103-150.

30. Singer, R. 1961. Mushrooms and Truffles. Mushrooms and Truffles.Leonard Hill Books Ltd. p.272. https://doi. org/10.1097/00010694-196206000-00012

31. Singh, V., P. Kumar, S. Kumar and K. Kumar. Yield performance of collected wild milky mushroom (Calocybe Sp.). Plant Archives. 2017. 17(1): 181-186.

32. Suman, M., G. Sharma and I.P. Sharma. In vitro Action of Temperature, $\mathrm{pH}$ and Light on Macrocybe giganteum (Giant Mushroom) Mycelia Growth. Research Journal of Agricultural Sciences, 2018; 9(1): 211-213.

33. Tandon, G. and V. P. Sharma. Yield performance of Calocybe indica on various substrate and supplements. Mushroom Research, 2006; 15: 33-35.

34. Thakur, M.P. and Harvinder K. Singh. Advances in the cultivation technology of tropical mushrooms in India. Jawaharlal Nehru Krishi Vishwa Vidyalaya Research Journal, 2014; 48(2): 120-135.

35. Thiribhuvanamala, G., V. Prakasam, G. Chandrasekar, K. Sakthivel, S. Veeralakshmi, R. Velazhahan and G. Kalaiselvi. Biodiversity, conservation and utilization of mushroom flora from the Western Ghats region of India. In Proceedings of the 7th International Conference on Mushroom Biology and Mushroom Products. 2011; 155-164. 